\title{
BUSINESS PROCESSES RECONFIGURATION THROUGH THE IMPLEMENTATION OF AN ENTERPRISE RESOURCE PLANNING SYSTEM
}

Cristiano Jesus,

University of Minho, School of Engineering, Algoritmi Center, Department of Production and Systems, Guimarães, Portugal
Rui M. Lima

University of Minho, School of Engineering, Algoritmi Center, Department of Production and Systems, Guimarães, Portugal
Crossref

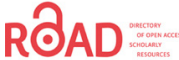

KOBSON

Key words: information technology, information systems, project management, business process management

Cite article:

Cristiano, J., \& Rui, M. L. [2021]. Business processes reconfiguration through the implementation of an enterprise resource planning system. Journal of Applied Engineering Science, 19(2) 488 - 497. DOI:10.5937/jaes0-27393 


\title{
BUSINESS PROCESSES RECONFIGURATION THROUGH THE IMPLEMENTATION OF AN ENTERPRISE RESOURCE PLANNING SYSTEM
}

\author{
Cristiano Jesus, Rui M. Lima* \\ University of Minho, School of Engineering, Algoritmi Center, Department of Production and Systems, \\ Guimarães, Portugal
}

The use of technology in organizations does not always produce the expected effects, because the cause-effect relationship in efficiency, productivity and therefore competitiveness is not linear. The available resources, ways of access and their capacities in terms of storage, processing and speed of response are known, however they are not always assimilated by the agents of the productive sector as they should to promote effective results and business agility. The research procedure adopted was a critical-descriptive analysis of a real case. Based on the bibliographic review on Business Processes reconfiguration and follow-up of an implementation project in a Brazilian company, a Business Model reconfiguration with ERP system implementation case was described and evaluated. The purpose of this article is to present a success case of Information Systems implementation project, to demonstrate the long way to go before reaching the results that makes such a project a successful project and to examine the impacts in the human resource perception. The research resulted in the description of an ERP implementation case, its evaluation based on perceptions, followed by critical discussion about barriers and risks inherent to projects of this nature. Although information technology has advanced a lot in the last decades in resources and functionalities, its cost has been significantly reduced, and its acquisition has been greatly facilitated, implementation is not a trivial activity. The article can serve as a guide for characterization of risks and sensitive aspects in reconfiguration projects for organizations that wish to achieve effectiveness in this type of project.

Key words: information technology, information systems, project management, business process management

\section{INTRODUCTION}

Since the 1990s, organizational reconfiguration frameworks have been used and this theme remains relevant because recent 14.0 requirements require special care with business models [1]. Therefore, companies must structure their organizational architecture by changing the way they work and committing themselves to continuous improvement, using information technology more effectively, associated with the development of human resources. It is possible to identify in the literature a considerable concern in 14.0 implementation projects aimed at organizational reconfiguration [2].

The organizational configuration that aims at the yield of assets based exclusively on mass production has been much discussed. If businesses have customer-centered actions, the market loses borders, competition becomes fiercer and the most immediate objectives become more volatile. In view of this, the ability to align business almost instantly with current demands is an imperative, at the risk of them gaining proportions so large that it is no longer possible to adapt without having to reconstruct the business model, which may be unfeasible. To achieve this alignment, companies must restructure their organizational architecture by changing the way they work and committing themselves to continuous improvement, using information technology more effectively, associated with the development of human resources [3].
It is thus necessary to have a more comprehensive vision of the company and the businesses in which it participates. In this context, the quality of products and services is an obligation, as well as the need to adapt quickly and efficiently to market changes. To help companies increase their productivity and be more efficient and competitive, there is an infinity of technological resources that promise to speed up and integrate internal processes and even between customers and suppliers. These benefits vary according to the investments and especially the methods used to implement and apply all this technology. One can invest a lot but obtain a return below expectations due to the way Information Technology (IT) is viewed within the business. Information is a vitally important asset of organizations and the way it is manipulated can determine their competitive capacity. The observation of how knowledge is developed and stimulated to the flow it travels between all processes is important to maintain its quality and rationalization. In a deficient process, time lost in unnecessary activities may never be recovered. This situation, at the very least, hold back the company's competitive evolution, while its competitors advance. In a market of global proportions, the impact of such a fact only tends to increase.

Information technology allows the manipulation and consumption of information in digital form, promising to make the processes more flexible and agile. That is why IT has been widely employed in companies since the 1950s, 
however, in the 1990s, they discovered that although they invested heavily in IT equipment and systems, productivity did not increase in the expected proportion, and information did not circulate and was restricted to a privileged few. According to Dewan and Ren [4], IT investments in the U.S. companies increased by $24 \%$ from 1995 to 2000. In 2004 alone, spending on equipment and software grew $41 \%$ since last year. However, the authors state that the expression "Does IT Matter?" has become famous among the main agents of this scenario. This question is quite important because even in scientific research the theme of reconfiguration of business models is focused on the adoption of technology, without presenting solutions to the implications that arise from it and to other equally relevant issues that are adjacent to them. In a systematic review of the literature on Industry 4.0, Jesus and Lima [5] identified that 12 articles out of a total of 21 of the Fundamental Concepts category had as their main focus the technological requirements. These authors consider that technological transformation occurs differently in each case, even if it has been guided by generic implementation frameworks and models. That is why success stories are important, not to be copied, but to report successful experiences as a reference for decision making and future research.

Although much has evolved in that direction, the more the technology develops and becomes more accessible, the greater the impulse of managers for filling the carts in the technological supermarkets seduced by the miraculous promises of connectivity and digital automation [6-8]. Several studies indicate the importance of strategic analysis guided by the systemic approach, which involves all areas of the company at the time of adopting any technology or tool with the aim of gaining competitiveness [9-11].

The objective of this article is to analyze a case of implementing information systems in an integrated way with human resource management, in an environment focused on continuous improvement and in a situation where information technology is used as an enabling resource in the process of organizational change. This analysis seeks to verify the potential of this process to help organizations visualize their markets and be agile in making decisions to maintain their competitive capacity. In a more detailed way, it can be considered that the objectives of this work are the following:

1. To confront the situation of the pre-implementation, company with the competitive difficulties predicted by the literature in a situation of increasing competition.

2. Analyze the importance of IT for the management of Business Processes in general.

3. Systematize the strategic decisions of the company according to its competitive positioning and present the new products and services resulting from these decisions.

4. Present the implementation of information systems in the company and analyze the convergence between it and the theoretical recommendations provided in literature.

5. Present and comment on the results obtained by the company and recommend procedures that increase the chances of success in implementing information systems.

\section{THEORETICAL BACKGROUND}

In process-based organizations, there is an alignment between the company's strategic objectives, its processes, human resources and information technology in use involving three distinct areas: business management, business processes and information technology support systems $[12,13]$. Table 1 below summarizes the difference between a traditional and a process-based organization:

Table 1: Transition from a traditional to a process-based organization, adapted from [14, 15]

\begin{tabular}{|c|l|}
\hline $\begin{array}{c}\text { Traditional organiza- } \\
\text { tion }\end{array}$ & $\begin{array}{l}\text { Process-based organiza- } \\
\text { tion }\end{array}$ \\
\hline Focus on competences & $\begin{array}{l}\text { Flexibility and expansion in } \\
\text { staff competences } \\
\text { Market and customer ori- } \\
\text { ented }\end{array}$ \\
\hline Hierarchical structure & Project-based guidance \\
\hline Emphasis on efficiency & $\begin{array}{l}\text { Emphasis on efficiency and } \\
\text { effectiveness }\end{array}$ \\
\hline Tasks outlined & $\begin{array}{l}\text { Market and customer orient- } \\
\text { ed, wide variety of tasks }\end{array}$ \\
\hline Limited need for training & $\begin{array}{l}\text { Wide variety of knowledge, } \\
\text { continuous learning pro- } \\
\text { cess. }\end{array}$ \\
\hline
\end{tabular}

Therefore, process-oriented organization does not adopt information systems and information technology as simple tools for discrete operations, but as the fundamental means of communication between functional areas. This is due to the organization structure that evolves from the traditional mechanical-deterministic composition to an organic-functionalist arrangement that begins and ends with the client, in the value perceived by him. This organization of work with a focus on the client provokes changes in the traditional hierarchical structure so that decision making takes place within projects and no longer from specific positions, projects that in practice make it possible to guide by continuous improvement because what becomes the organizational culture is the articulation of competencies for the optimization of processes with a view to their conformity with the external environment and no longer the isolated actions of specialists for the deliberation of internal occurrences.

In its version of BPR - Business Process Reengineering, namely BPR2 - Business Process Rearrangement and Renaming, Khosravi [16] proposes a methodology that leads the organization to reassess what it considers to be internal and external values that are perceived 
by customers. The whole model, therefore, focuses on identifying means of creating values and arrangements, resources and ways of promoting these values. From this perspective, any approach that maintains an exclusive focus on technology and its capabilities loses its meaning.

Leonardi and Bailey [17] state that technological transformation, or transformation mediated by technology, as the meaning of expression is assumed, always occurs for the purpose of enabling distributed work through the optimization of communication for the purposes of creation, visualization, modification and analysis of a wide range of knowledge. Thus, for these authors, the technological transformation needs to dramatically focus on the effectiveness of the distribution of work.

Karimi et al [18] consider that information systems, such as ERP systems, if in their implementation no other dimensions of the business environment than the technological dimension are observed, they cannot do beyond the traditional transaction processing, which is very little relevant to the current scenario of demands for partnerships and collaboration. Drnevich and Croson [11] believe that if competing requires investments in technology, a management strategy that does not consider governance, competencies and flexibility, puts the organization on a difficult course from an economic point of view as costs increase without a counterpart in results, especially in dynamic environments, which are increasingly common.

Gouillart and Kelly [19] present a view based on fundamental concepts presented also by Segatto et al [20] and Novak and Janes [21] which support the same thesis, on the need to look at the company as a living organism, the biological company, endowed with mind, body and spirit, requiring a comprehensive treatment. According to the authors, considering information technology as the only important factor in the restructuring of processes in order to obtain competitiveness is a mistake. Besides information technology, for the authors it is necessary to pay attention to the following items: reconfiguration of the entrepreneurial mind that constitutes the concern with communication, seeking ways to improve it; restructuring of the body of the company and formulation of operations strategies, allocating resources by activities in order to reorganize and rationalize the work through the alignment between the infrastructure and strategic objectives; revitalization, or growth made possible by the link between the body of the company and the environment.

For Love et al [22], organizational and non-technical barriers represent the main challenge. Successful implementation depends on conscientious management regarding changes in behavior and organizational structure. Investing in people, in new profiles and new challenges, allows the company to recreate itself with an environment favorable to the dissemination of knowledge and adaptation to environmental changes. These same authors call this action, social planning, and consider that the objective in this field should be to specify its im- plications, such as the description of the organization, professionals, tasks, career plan and incentives and, in parallel, identify problems in recruitment, training and habits. Therefore, the authors recommend some human resource management techniques: (1) Employee development, identification of responsibilities, development of decision making capacity; (2) Self-management and multi-functional teams with different types of professionals whose nomination of leaders is not conditioned to the position, but to the level of familiarization and involvement with the process; (3) restructuring of the organization with definition of the characteristics of the teams and efficient distribution of professionals according to their abilities; (4) production of tasks in which the competences and training needs for each defined position are determined; (5) adoption of incentives to eliminate barriers, motivate participation and commitment to the company's strategic objectives.

McKay and Radnor [23] and Palma-Mendoza et al [24] state that the main causes of resistance are real threats, that is, anything that seems capable of affecting or altering personal position or prestige or altering what is valued at work, changes imposed, lack of confidence in those who promote change and also the belief that something has been neglected. To minimize these problems as much as possible, the authors recommend planning actions involving participation, communication and training. Due to the complexity of this type of change, it is not recommended that they happen abruptly. Besides the changes in the information systems, together, the organization and distribution of tasks and, consequently, the way of working, it should be considered that the reality of people will change. Therefore, they must be progressive and planned with investments in training and incentives.

Ashayeri et al [25] reinforce that it is important to adopt process transformation and optimization encompassing quality policies to ensure continuous improvement, so that the project is characterized by three situations: (1) the reengineering of business processes in which process redesign occurs through the application of technologies to gain drastic improvements in critical performance indicators, then (2) continuous process improvement, in which the workflow with functional activities is improved, and finally, (3) a permanent review and restructuring of processes that eliminates non-value-adding activities and improves response time capacity. According to the authors, the first element of transformation demands an innovative vision of the mission and can result not only in the drastic restructuring of processes, but also in mission change and strategic decisions. The second item makes organizations able to improve teams in process-oriented activities, while the third helps companies to stay within their existential mission.

Kohlbacher [14], Mohapatra [26] and Love et al. [22] propose that projects of implementation of information systems and consequent adaptation of productive systems, should be organized with the following phases: analysis of the environment, analysis of the workflow, 
information engineering, performance indicators, strategic automation and changes in management. During the environment analysis, the elaboration or repositioning of the organizational strategy takes place considering the organization's mission, internal and external factors, as well as other constituent elements of the organization as a socioeconomic institution. During the workflow analysis, corresponding to the construction of the organizational architecture from the strategic conception of the corporation, the design of the processes and sub-processes carried out through the appropriate techniques of the process management area, or Business Process Management (BPM), is performed [27]. The information engineering corresponds to the establishment of the relationship between business processes and information systems. In the next phase, performance indicators are developed that monitor the level of maturity of processes and organizational functions. In the strategic automation phase, the infrastructure configuration and adoption of a technological apparatus are carried out, which enable the automation not only of tasks, but also of the information flow. Here, ubiquitous computing, automated and integrated machines, sensors, communication devices, 3D printers, data collectors, artificial intelligence and others are used [28]. Finally, in the change in the management of processes with focus on the scenario of great demand for agility, the organization of work undergoes major changes from the adoption of project-oriented activities, participatory management, continuous learning, Knowledge Management (KM), and the development of the concept of collective intelligence. It can be understood by the description of these phases, that the organizational culture needs to align with a perspective that the capacity of an organization is not in the sum of the specialties of its human resources, but in the way, it is managed the articulation of competences with a view to strategic objectives.

\section{RESEARCH METHODOLOGY}

The methodology that was adopted is that of a critical-descriptive analysis of a real case based on a theoretical framework presented in Literature Review. The case study was developed from an experiential analysis of the implementation of an Enterprise Resource Planning (ERP) system, by a multinational company, based in France, in its plants in Americana and Campinas, cities in the interior of São Paulo. A case study of an organizational structure is a research procedure of a quantitative or qualitative nature that consists of a detailed examination for a certain period of time of the dynamics of that social organization. The number of variables analyzed is usually high. The aim is always to increase knowledge about the environment to formulate hypotheses or study the changes likely to take place over time in the context studied [29].

In the research in question, the study is qualitative, and the aim is to understand the experiences lived on the basis of the competences of the people involved. In a more detailed way, the route covered of this case study is the following: (1) Analyze the importance of IT for the management of Business Processes in general; (2) systematize the strategic decisions of the company according to its competitive positioning and present the new products and services resulting from these decisions; (3) present the implementation of information systems in the company; (4) present and comment on the results obtained by the company, and recommend procedures that increase the chances of success in implementing information systems.

The results of the implementation of the ERP system will be described in the following section and then evaluated by means of a survey prepared and applied among all the employees involved in the project.

\section{DESCRIPTION OF THE CASE STUDY}

SL Corporation was an international company with operations in over 100 countries and employing 64,000 professionals in the following oil, services and product segments for resource measurement (water, electricity and gas), electronic transactions and communication.

With sensitive transformations in the Brazilian market and fierce international competition, this type of organizational structure became no longer bearable. This new panorama forced the company to be concerned in improving their management models and performance indicators values. Thus, the company defined objectives such pursuing policy of quality, improving production flow and introducing the Lean Manufacturing principles and tools. Additionally, it was also interested in augmenting the level of the automation, namely through the introduction of electronic data collection, automatic quality control, integration between manufacturing and design projects through new CAD/CAM systems, preventive maintenance of equipment, and electronic communication between suppliers and customers. The company started a business transformation project that basically consisted of restructuring the business processes and changing the functional orientation to processes, culminating in the implementation of an ERP system. The organization of the work was done from the arrangement as can be seen in Table 2 .

External consultants provided support in the creation of the work plan, training and follow-up. In order to design the objectives, several analyses of the company's vision and strategies were made, so that some questions were defined and disseminated throughout the company, such as: "Where are we? What are our problems today and for the future? What are the new opportunities? How to maintain our market and how to conquer new ones? Who will be our competitors?".

Through evaluation meetings and information analysis that portrayed the company's situation, it was concluded that the main problems were those arising from a lack of competitiveness in a globalized market. The focus on product quality, efficient services and meeting customers' needs were considered as extremely important 
Table 2: Team organization and responsibility

\begin{tabular}{|l|l|l|}
\hline \multicolumn{1}{|c|}{ Team } & \multicolumn{1}{|c|}{ Members } & \multicolumn{1}{c|}{ Responsibilities } \\
\hline Implementation committee & $\begin{array}{l}\text { Project manager, directors, macro-process } \\
\text { leaders, key-users, external consultants }\end{array}$ & $\begin{array}{l}\text { Organization architecture redesign, } \\
\text { implementation management }\end{array}$ \\
\hline Multifunctional teams & $\begin{array}{l}\text { Key-user (leader), technical experts, IT } \\
\text { professional }\end{array}$ & $\begin{array}{l}\text { Implementation of organizational } \\
\text { changes and the system information } \\
\text { (setting parameters, tests, evaluation, } \\
\text { and follow-up) }\end{array}$ \\
\hline
\end{tabular}

items for success. The company's goal was to consolidate its leadership in the market where it operated, providing quality products and services. To this end, guidelines were established regarding the customer, solutions, value and effectiveness as shown in Table 3.

The redesign of processes is one of the most complex stages of the organization's restructuring projects. This redesign must be based on the fact that all tasks involving a process must be activities that add value to the service or the final product. Therefore, at a first stage, current processes and activities should be potentially streamlined and optimizable, and this should be done in a way that produces measurable results and allows continuous improvement later on. To achieve these objectives, a methodology was used that comprises the stages of identification, mapping, and optimization of processes.

In this specific case, a brainstorming was performed in which the representatives of each area listed all their functions or tasks. Subsequently, these functions were organized and given the name of macro activities, which were then detailed to break down into basic activities. This survey was done only at these two levels at first, because the objective should be to identify processes through the relationship between tasks. After this survey, it was necessary to map the operations, that is, to relate them in such a way that their representation is legible, in order to later identify the relationships between the processes and tasks, the inputs and outputs, and the clients and suppliers of each process. For this, BPMN Business Process Management and Notation modeling language was used, with the purpose of representing the processes of the company and make it easier to identify the beginning and end of the process and inconsistent connections. From this flow it is possible to detect which are the customers and suppliers of the process, the inputs and outputs, and the indicators used. With the macro-activities and activities well visualized in a clear and

Table 3: Strategic action guidelines

\begin{tabular}{|c|c|}
\hline Dimension & Guidelines \\
\hline Customers & $\begin{array}{l}\text { 1. Consider the entire value chain in the acquisition of resources, from production, transportation } \\
\text { and distribution to the needs of end customers, in order to maximize the value of the offer; } \\
\text { 2. Deepen the partnership relationship with customers seeking to meet their needs; } \\
\text { 3. Understand the environment in which the company's products and services operate, in order } \\
\text { to identify new opportunities to increase efficiency, eliminate unnecessary tasks and stream- } \\
\text { line transactions. }\end{array}$ \\
\hline Solutions & $\begin{array}{l}\text { 1. Combine products and services to obtain solutions, that is, add value-adding services to the } \\
\text { products; } \\
\text { 2. Use the best available talent to generate innovative solutions, also including third parties, if } \\
\text { necessary for a more complete solution offering. This requires training and personal develop- } \\
\text { ment that will ensure that the competence and solutions are found. }\end{array}$ \\
\hline Value & $\begin{array}{l}\text { 1. Where savings are made through increased use of capital investments or reduced losses or } \\
\text { high margins, an effort should be made to share these gains with employees in an equitable } \\
\text { manner. The greater risk that accompanies better value creation should also be shared; } \\
\text { 2. Services should be available to any supplier or consumer, whatever their position in the supply } \\
\text { value chain and resource consumption. When faced with customers with different objectives } \\
\text { or possible conflicts of interest, the guiding principle should be to provide the highest value. }\end{array}$ \\
\hline Effectiveness & $\begin{array}{l}\text { 1. Supervise marketing programs, engineering projects and production units to provide custom- } \\
\text { ers with the best service with maximum value. Each action should help to win new customers, } \\
\text { increase market share and profit margin; } \\
\text { 2. Exploit information technology, to gather and share information on customer needs, guide the } \\
\text { development of products and services around the world, disseminate the range of capabilities } \\
\text { of the company in order to serve the customer in the best way and ensure that employees } \\
\text { remain the best in the business. }\end{array}$ \\
\hline
\end{tabular}


concise way, it is already possible to raise the points of attention with customers and suppliers as well as their origin or cause, allowing to explore opportunities for improvement of the process.

Another important aspect is the verification of the reports that are currently being used, in order to check their use, their usefulness and finally the need to make it possible as an important document for the processes. After the evaluation meetings and the needs for integration and improvements were adequately defined, the implementation phase began. In this phase, organizational structures and information technology were reviewed with the purpose of attending adequately to the process design. At this point, the organizational structure used was assessed and then reformulated so that process-oriented work was possible. After the restructuring of the processes and the organization, it was necessary to implement an information system that also met this new orientation. To do this, the present situation had to be mapped out in order to make the right decisions. The available resources, including equipment and systems, the activities that these resources covered, the users and the problems were then surveyed. New decisions in terms of systems should be planned in a decentralized way, that is, it should not only be the IT personnel who decide on systems, but the organization as a whole. New plans are expected from information technology that allow the integration, in real time, of all processes of the organization and development and applications of new technologies.

\section{EVALUATION OF THE ERP IMPLEMENTATION}

SL Corporation has two units in the resource measurement segment in Brazil and, even before the organization's restructuring, both were separate companies, although they were part of the same business group. Both had their own accounting, finance, sales, etc. departments. After the restructuring, they merged completely, creating a single accounting process for both, as well as sales, IT and all other processes. After almost two years of implementing the ERP system and the organizational changes, in terms of invoicing, the company recovered the market it had, since the profit per employee increased. This means it hears staff cuts although it has not been alarming affecting only those positions that have become obsolete. The company chose to offer training to adapt to the new organizational scenario. Although the gains regarding the market and customers have been significant, it is also important to highlight other points where the company has made great improvements. The company started to work in a much more integrated way, making it possible to detect problems and solve them more quickly. Procedures that were previously done once a month and still consumed almost 30 hours of processing, began to be carried out at least once a day and besides consuming not one hour of processing. This allowed for faster decision making and also to meet customer needs. Another very important improvement factor is the ease and speed with which any employee in the company today can extract information from information systems, something that previously only IT professionals could do and still need deadlines that took months. Another important gain was the achievement of an environment that encourages participation in the company's strategic decisions. Never before have people had so many possibilities and opportunities to suggest changes and improvements in the company's processes and activities. This aspect was very important to consolidate the organizational changes and also to establish a process of continuous improvement.

Even though the system is implemented and in operation, it does not mean that the project is over. It takes months of monitoring and reviewing the planned processes. Something that can help in this task is an opinion poll for the survey of factors still of potential change. A survey was conducted among SL Corp. employees by the implementation team. The form was sent to 55 people and 17 responded, thus obtaining an effective return of $30.9 \%$.

Regarding process organization, most of the answers indicate that this organization model is more efficient $(84 \%)$, more rational (82\%) and promotes teamwork $(76 \%)$. However, opinions are divided in relation to the reduction of bureaucracy, agility in decision making and simplification of processes. The perception in these items is slightly more positive than negative so that they are between $53 \%$ and $59 \%$. Spontaneous responses indicate recognition of the value of a change in management model provided it is accompanied by a change in mentality. There is a predominant understanding of the improvement in the organizational climate and greater possibility of reevaluation of competencies. On the other hand, negative responses are clarified with notes such as difficulties in the flow of documents that are required by quality standards regarding ISO certification, documents that also cause duplicity of information that needs to be reported. The emergence of the figure of the process leader is interpreted by some as a bureaucratic aspect that has been added, because unlike linearity, interventions are necessary and slow decision-making by process leaders has been pointed out. However, more than $70 \%$ of the interviewees say they are encouraged to question the leaders and most of the time they do so when they believe they can contribute. Other problems were also mentioned as limitations in the ERP system and organizational problems that remain with suppliers in a way that prevents significant improvement in internal processes.

As for the perceived reason for migrating from the functional model to process management, respondents fluctuated between unanimity in some responses and above $90 \%$ in others. Answers related to objectives such as streamlining decisions, delegation of responsibilities, cost reduction, promotion of teamwork, renewal of values and disclosure of new talent were obtained. The responses indicate that there is clarity about the purposes of the organization with the new management model. 
Respondents were asked if they had any prior knowledge about the process management model and only $13 \%$ responded that they already knew from reading articles and courses at the universities they attended, however only one response was negative regarding their judgment of the ability to work with the new model, and also only one respondent who wished to return to the old work model.

Among the strong points of the process management model cited in the survey were the commitment of senior management to the reconfiguration project, improvement in the work environment with changes in the hierarchical structure and greater autonomy, and the possibility of cooperation in decision making, greater efficiency of technological resources and greater rationality in the integration of operations.

Among the weak points are the lack of changes in the career plan and salary policy, although the company has evolved in a visible way, persistence of old problems such as management relations, resistance to innovation, low quality information that circulates informally, delays in launching new products and still little experience in offering services.

\section{DISCUSSION}

The need to provide quality products accompanied by a number of other advantages such as good service, low prices, meeting deadlines, speed and efficiency in deliveries, among others, is forcing corporations to review their values and their vision of how to work. The indiscriminate application of computers at various functional and administrative levels does not, by itself, ensure competitiveness. Moreover, in the current times, the importance of analyzing their role within a social context is eminent. The perception of the importance of people as a potential factor of competitiveness is something growing in the business world. The implementation of technologies and information systems, without including them in a context of organizational strategy, may result in some benefit at first, but over time this apparent improvement may revert into problems what should be a solution. Information technology cannot be considered as a way to solve all the problems of companies, nor as a key in the search for competitiveness in a market of global proportions. In fact, it is merged among business management strategies, taking for itself the responsibility to simplify and streamline the flow of information between processes, rationalize and reduce the time of operations that do not add value to products, and support decision making in the midst of constant changes. However, without a new vision that results in an integrated and methodical organizational restructuring, information technology can become a heavy burden for companies, not effectively helping the escalation of barriers to achieve better conditions to compete and prosper. Factors such as customer, quality, organizational goals and objectives, performance measurement systems, manufacturing strategies, human resources and technology as an integration factor and facilitator of the information flow between these processes make up the basic variables that companies must take as references in a strategic management perspective.

This way of working, based on Business Process implementation theories is very powerful, because it offers good results and flexibility besides allowing the decentralization of decisions. For having met this requirement the analyzed company managed to increase its intellectual capacity, speed in solving problems and consequently its competitive level. Naturally, the main challenge of the company in the implementation were the organizational and not technical barriers, as foreseen in the literature. It is important to focus on behavioral aspects, attitudes and perceptions of people; task rotation as well as new remuneration and career policies can also be useful.

Currently, the processes rely on their leaders and on the company's callers, key-users, who are responsible for coordinating all employees in a process of continuous improvement, always seeking to identify the deficiencies and, with work fronts, remedy them. The deficiencies are usually identified through management and maturity indicators that have been prepared with the objective of obtaining concise and strategic information. These teams are always multifunctional, and their leaders are not elected for the position, but for their involvement with the problem detected. It should also be noted that quality policies, applied jointly or following the reconfiguration project, become powerful tools for the corporation to create a process of continuous improvement.

In this case, SL Corp., after the changes and the implementation of the ERP system, started to invest in quality policies that valued the attitude and collective participation for the quality of products and services, in addition to providing the development of a good working environment. The company achieved ISO 9002 certification and promoted a movement of incentive and motivation for participatory contribution, creating teams for research and implementation of improvements and problem solving, and for implementation of TQM. Another important aspect is that IT is no longer a centralized department but a segment of all the organization's processes. In general, the profile of professionals also needed to change. A systems analyst, for example, needed to expand his exclusively expert vision to understand the business; the same happened with the other professionals in the organization, because everyone needed to know the process as a whole, including information technology.

After the implementation of the reformulations in the processes and the implementation of the ERP system, the company summarized all its experience in a reference guide that was standardized for use by the entire corporation. This manual consists of recommendations for process restructuring projects. From the experience lived in this process, we can point out some of the more relevant recommendations regarding the roles of the various agents. 
For the company, top management has an essential role in the success of the project, being responsible for defining the business objectives, electing the project manager, allocating the necessary internal resources, following the project and validating each macro phase. As for the steering committee, consisting of managers involved in functional areas of the project, it is necessary that they meet periodically to validate the choice of processes and ensure that all areas are well targeted, ensure that the objectives are achieved and validate each phase of the project. The project manager should choose key users and check their availability, define and maintain planning, both goals and details, use standard templates to ensure inter-operability, obtain validation of new processes and possible modification suggestions in the organization, avoid customizations, submit customizations for validation and approval if really needed, supervise key users and end-user training, and report the use of licenses to the technology segment. Key users form a multi-functional team and must have a global view and mastery of the functions they perform. Their main tasks are to receive training and multiply knowledge among other users, understand standardization efforts, redesign processes, perform tests and create procedures and user guides for users. The IT team must be responsible for the equipment, networks, databases, etc. of the implementation, being responsible for installing and configuring the equipment and the network, managing the use of the system, preparing test and operation environments and creating security policies for users.

Since external consultants have the functional knowledge about the package, they are the ones who must train the users and the informatics personnel, follow the project progress, provide functional support, raise project management problems and develop customization program, if necessary. Besides process organization, ERP systems and information technology, many other factors are important for the success of companies. Because of this, this work cannot be considered a definitive recipe for organizations to succeed in their goals of being competitive and gaining a privileged place in today's fast-growing market.

\section{CONCLUSION}

Research has shown that it is not appropriate to resort to expedients that promote major transformations in need of an urgent reaction to the imminent risk of discontinuity, since the efforts and investments for restructuring of this size are considerable, and that changes of this kind are progressive and occur at a pace that is also in line with progress in organizational culture. Therefore, once such a project is carried out, the adoption of quality policies associated with continuous improvement and permanent care with human resource management is paramount.

Therefore, as described in the following paragraphs the aimed objectives of this work were achieved. As predicted in the literature, information technology has proved to be a viable resource for strategic management, that is, it corresponds to the means of achieving strategic objectives, and therefore IT should never be considered the objective itself. The approach of redefining organizational guidelines in line with the business environment and the relationship with customers and partners is right, in order to also consider services that add value to products, only then to reconstruct the organizational architecture through the deployment of business processes.

It is worth considering that processes are integrated activities that cross functional areas and there is only integration where there is communication. The function of information technology and information systems is to automate this communication so that it occurs efficiently and its implementation should not obey only technical parameters, it should be the result of the work of a multidisciplinary team that observes the perfect capacity of adherence of technological resources to business processes aligned with the mission of the organization.

The company redefined its strategic objectives according to the new environment imposed by the new entrants so that they imposed a competition that until then the firm was not ready to face. The guide to strategic actions developed as part of the reconfiguration of the business model focused on the "customers", "solutions", "value" and "effectiveness" dimensions became a central and critical element in the whole project.

As predicted in the literature, participatory and project-oriented management was essential, but it was possible through the establishment of an organizational culture aimed at cooperation and the articulation of competencies. Much of the success achieved by the project described in this article has been due to the care taken in dealing with personal resistance, motivations and the training program implemented.

Results obtained and procedures recommended that increase the chances of success in implementing information systems are described with detailed in section 5 and 6. In addition, the choice of the organization to adopt measures based on critical success factors in order to contain at first the entropy process and then promote changes in its business model and organizational culture on new foundations was right and seems to be a promising opportunity for further research. Other studies, quite concerned with the current trends and that can be seen as a deepening of the subjects treated in this work, are those related to the implementation models of Industry 4.0.

\section{ACKNOWLEDGMENTS}

This work was partially supported by FCT-Fundação para a Ciência e Tecnologia within the R\&D Units Project Scope: UIDB/00319/2020. 


\section{REFERENCES}

1. Mittal, S.; Khan, M.A.; Romero, D.; Wuest, T. (2018). A critical review of smart manufacturing \& Industry 4.0 maturity models: Implications for small and medium-sized enterprises (SMEs). Journal of Manufacturing Systems, 49, 194-214, doi:10.1016/j. jmsy.2018.10.005.

2. Veile, J.W.; Kiel, D.; Muller, J.M.; Voigt, K.-I. (2019). Lessons learned from Industry 4.0 implementation in the German manufacturing industry. Journal of Manufacturing Technology Management, doi:10.1108/ JMTM-08-2018-0270.

3. Alcacer, V.; Cruz-Machado, V. (2019). Scanning the Industry 4.0: A Literature Review on Technologies for Manufacturing Systems. Engineering Science and Technology, an International Journal, 22, 899-919, doi:10.1016/j.jestch.2019.01.006.

4. Dewan, S.; Ren, F. (2011). Information Technology and Firm Boundaries: Impact on Firm Risk and Return Performance. Information Systems Research, 22, 369-388, doi:10.1287/isre.1090.0261.

5. Jesus, C. de; Lima, R.M. (2020). Literature Search of Key Factors for the Development of Generic and Specific Maturity Models for Industry 4.0. Applied Sciences, 10, 5825, doi:10.3390/app10175825.

6. Ongena, G.; Ravesteyn, P. (2019). Business process management maturity and performance. Business Process Management Journal, doi:10.1108/ BPMJ-08-2018-0224.

7. Gooijer,J.de.(2000). Designingaknowledgemanagement performance framework. Journal of Knowledge Management, doi:10.1108/13673270010379858.

8. Walczak, S. (2005). Organizational knowledge management structure. The Learning Organization, doi:10.1108/09696470510599118.

9. Muller, J.M.; Kiel, D.; Voigt, K.-I. (2018). What Drives the Implementation of Industry 4.0? The Role of Opportunities and Challenges in the Context of Sustainability. Sustainability, 1-24, doi:10.3390/ su10010247.

10. Hunter, M. (2013). A Short History of Business and Entrepreneurial Evolution During the 20th Century: Trends for the New Millenium. Geopolitics, History, and International Relations, 5, 44-98, doi:10.2307/26805926.

11. Drnevich, P.L.; Croson, D.C. (2013). Information Technology and Business-Level Strategy: Toward an Integrated Theoretical Perspective. MIS Quarterly, 37, 483-509, doi:10.25300/MISQ/2013/37.2.08.

12. Leino, T. (2008). Stability and Creativity as Contradicting Values in Information Management. Journal of Cases on Information Technology (JCIT), 10, 2540, doi:10.4018/jcit.2008040103.
13. Chen, C.-K.; Tsai, C.-H. (2008). Developing a process re-engineering-oriented organizational change exploratory simulation system (PROCESS). International Journal of Production Research, 46, 44634482, doi:10.1080/00207540601182286.

14. Kohlbacher, M. (2010). The effects of process orientation: a literature review. Business Process Management Journal, 16, 135-152, doi:10.1108/14637151011017985.

15. van der Zee, Han.T.M. (1998). Rejuvenating the IT supply organization. Information Management \& Computer Security, 6, 55-65, doi:10.1108/09685229810209379.

16. Khosravi, A. (2016). Business process rearrangement and renaming: A new approach to process orientation and improvement. Business Process Management Journal, 22, 116-139, doi:10.1108/ BPMJ-02-2015-0012.

17. Leonardi, P.M.; Bailey, D.E. (2008). Transformational Technologies and the Creation of New Work Practices: Making Implicit Knowledge Explicit in Task-Based Offshoring. MIS Quarterly, 32, 411-436, doi:10.2307/25148846.

18. Karimi, J.; Somers, T.M.; Bhattacherjee, A. (2009). The Role of ERP Implementation in Enabling Digital Options: A Theoretical and Empirical Analysis. International Journal of Electronic Commerce, 13, 7-42, doi:10.2753/JEC1086-4415130301.

19. Gouillart, F.J.; Kelly, J.N. (1995). Transforming the organization; McGraw-Hill: New York, ISBN 978-007-034067-1.

20. Segatto, M.; Pádua, S.; Martinelli, D. (2013). Business process management: A systemic approach? Business Process Management Journal, 19, doi:10.1108/BPMJ-Jun-2012-0064.

21. Novak, R.; Janes, A. (2019). Business process orientation in the Slovenian power supply. Business Process Management Journal, 25, 780-798, doi:10.1108/BPMJ-05-2017-0130.

22. Love, P.E.D.; Gunasekaran, A.; Li, H. (1998). Putting an engine into re-engineering: toward a process-oriented organisation. International Journal of Operations \& Production Management, 18, 937-949, doi:10.1108/01443579810225531.

23. McKay, A.; Radnor, Z. (1998). A characterization of a business process. International Journal of Operations \& Production Management, 18, 924-936, doi:10.1108/01443579810225522.

24. Palma-Mendoza, J.A.; Neailey, K.; Roy, R. (2014). Business process re-design methodology to support supply chain integration. International Journal of Information Management, 34, 167-176, doi:10.1016/j. ijinfomgt.2013.12.008. 
25. Ashayeri, J.; Keij, R.; Broker, A. (1998). Global business process re-engineering: A system dynamics-based approach. International Journal of Operations \& Production Management, 18, 817-831, doi:10.1108/01443579810225478.

26. Mohapatra, S. (2013). Business Process Reengineering: Framework and Approach. In Business Process Reengineering; Springer Science+Business Media: New York, pp. 51-67, doi: 10.1007/978-14614-6067-1_3.

27. Lima, R. (2010). Integrating Production Planning and Control Business Processes. International Journal of Productivity Management and Assessment Technologies, 1, 172-193, doi:10.4018/978-1-60566-856-7. ch009.
28. Agostini, L.; Filippini, R. (2019). Organizational and managerial challenges in the path toward Industry 4.0. European Journal of Innovation Management, doi:10.1108/EJIM-02-2018-0030.

29. Yin, R.K. (2018). Case Study Research and Applications: Design and Methods, Sixth edition, SAGE Publications, Inc: Los Angeles, ISBN 978-1-50633616-9. 